\title{
ANALISIS KETERSEDIAAN AIR PADA DAS INDRAGIRI HILIR MENGGUNAKAN MODEL IHACRES
}

\author{
${ }^{1}$ Jusatria, ${ }^{2}$ Syahnandito, M. Gasali $\mathrm{M}^{1}$, Rezky Kinanda ${ }^{1}$ \\ ${ }^{1}$ Program Studi Teknik Sipil, Fakultas Teknik dan Ilmu Komputer, Universitas Islam Indragiri \\ ${ }^{2}$ Program Studi Teknik Sipil, Fakultas Teknik, Universitas Riau \\ Email: jusatria2901@gmail.com (korespondensi)
}

\begin{abstract}
The imbalance that occurs between the availability of water and the water needs needed in Indragiri Hilir requires a conseptual review and evaluation. The all-time distribution of water availability is greatly influenced by the distribution of rain throughout the year. Conceptual analysis of water discharge with the help of IHACRES software can help analyze DAS indragiri Hilir discharge. Rainfall-runoff modeling is used to predict the value against the runoff, using the IHACRES model. The IHACRES model produces nonlinear loss module parameters and linear unit hydrograph modules. AWLR will be used, namely Bt. Kuantan Rengat station, Rain Data which will be used from Tembilahan station and climatology used from Air Molek station. Determination of success in the model used the equations $R 2$ and $R$ to calculate the deviation that occurs. The calibration, verification and simulation phases begin in 2010-2015. The results of conceptual analysis of water discharge in Indragiri Hilir watershed, mainstay discharge results for irrigation purposes with a probability of $80 \%$ maximum discharge occurred in February by $4.33 \mathrm{m3} / \mathrm{s}$ and minimum discharge occurred in April by $0.34 \mathrm{m3} / \mathrm{s}$. Overall availability of water on site is available throughout the year. but it cannot be used for hydropower needs because the available discharge may be affected by tidal factors.
\end{abstract}

Keywords: IHACRES, rainfall-runoff, availability of water

\begin{abstract}
Abstrak
Ketidakseimbangan yang terjadi antara ketersediaan air dan kebutuhan air yang diperlukan di Indragiri Hilir memerlukan peninjauan dan evaluasi yang konseptual. Distribusi ketersedian air sepanjang waktu sangat dipengaruhi oleh distribusi hujan sepanjang tahun . Analisis konseptual debit air dengan bantuan software IHACRES dapat membantu menganalisis debit DAS indragiri hilir. Pemodelan rainfall-runoff digunakan untuk memprediksi nilai terhadap runoff salah satunya yaitu menggunakan model IHACRES. Model IHACRES menghasilkan parameter nonlinier loss module dan linier unit hydrograph module. AWLR akan digunakan yaitu stasiun Bt. Kuantan Rengat, Data Hujan yang akan digunakan yaitu dari stasiun Tembilahan dan klimatologi yang digunakan dari stasiun Air Molek. Penentuan keberhasilan pada model digunakan persamaan $R 2$ dan $R$ untuk menghitung simpangan yang terjadi. Tahap kalibrasi, verifikasi dan simulasi dimulai tahun 2010-2015. Hasil analisis konseptual debit air pada DAS Indragiri Hilir, hasil debit andalan untuk keperluan irigasi dengan probabilitas $80 \%$ debit maksimum terjadi pada bulan Februari sebesar 4,33 m3/s dan debit minimum terjadi pada bulan April sebesar 0,34 m3/s. Secara keseluruhan ketersediaan air di lokasi tersedia sepanjang tahun. tetapi tidak bisa digunakan untuk kebutuhan PLTA karena debit yang tersedia mungkin dipengaruhi faktor pasang surut
\end{abstract}

Kata kunci: IHACRES, rainfall-runoff, Ketersdiaan Air

\section{PENDAHUlUAN}

Air yang berada pada Daerah aliran sungai (DAS) Indragiri Hilir yang kadang meluap secara tiba-tiba ke permukaan perlunya dilakukan peninjauan dalam evaluasi debit tersebut. Untuk itu perlu ditinjau secara konseptual karena kebutuhan air yang terus meningkat seiring dengan laju pertumbuhan penduduk setiap tahunnya. Kecenderungan yang sering terjadi adalah adanya ketidak seimbangan yang terjadi antara ketersediaan dan kebutuhan air yang 
diperlukan. Untuk mencapai keseimbangan antara kebutuhan air dan ketersediaan air di masa mendatang, diperlukan upaya pengkajian terhadap komponen tersebut. Distribusi ketersedian air sepanjang waktu sangat dipengaruhi oleh distribusi hujan sepanjang tahun. Pergerakan air yang dapat dideteksi dan didekati dengan beberapa persamaan matematika. Persamaan tersebut mencerminkan proses pengalihragaman dari hujan menjadi aliran yang dapat ditiru dan disederhanakan serta diwujudkan dalam bentuk model, yang disebut dengan model hujan aliran. Pendekatan yang digunakan untuk membangun suatu pemodelan curah hujan menjadi debit aliran sungai dimana dapat menentukan parameter yang dinginkan oleh peneliti. Pada penggunaan pemodelan ini banyak parameter yang berpengaruh seperti input data, nilai dari parameter yang ditetapkan, struktur pemodelan dan lain-lain. Salah satu cara yang umum dari suatu pemodelan adalah mengembangkan model dari suatu pemodelan yang kemudian di modifikasi.

Pemodelan rainfall-runoff yang digunakan biasanya dikarenakan sering terbatasnya ketersediaan data debit dari aliran sungai yang ditinjau. Dalam pemodelan rainfall-runoff ini biasanya melibatkan analisa statistik untuk memprediksi data kedepan. Karena banyaknya model yang ada saat ini salah satunya yang akan digunakan adalah Model IHACRES yang merupakan model hujan aliran yang cukup dikenal dan banyak diaplikasikan di beberapa negara di dunia oleh para praktisi dan peneliti. Model IHACRES (Identification of Unit Hydrograph and Component Flow from Rainfall, Evaporation and Stream Flow Data) dikembangkan di Inggris, dengan mendeskripsikan hujan aliran menjadi dua sub proses yakni sub proses vertikal yang digambarkan oleh Non Linear Loss Module dan sub proses lateral yang diimplementasikan melalui Linear Unit Hydrograph Module (Indarto, 2010). Pada daerah Riau banyak penelitian yang telah berhasil menggunakan model tersebut sehingga DAS indragiri juga perlu dilakukan penyelidikan secara konseptual mengenai kapasitas ketersediaan air yang bisa digunakan oleh masyarakat melanjutkan dari penelitian saya sebelumnya mengenai analisa aliran DAS indragiri Hilir menggunakan Model hidrologi IHACRES pada DAS tersebut.

\section{TINJAUAN PUSTAKA}

Banyaknya model rainfall-runoff saat ini yang sudah dikembangkan diantaranya: tank model (sugawara, 1995), IHACRES (Ye, 1997), HBV (Lindstrom, 1997), SMAR (Tan dan O'Connor, 1996), TOPMODEL (Beven,1986), Xianjiang (Jayawardena dan Zhou, 2000) dan lain - lain.

\subsection{Pemodelan}

Pemodelan yaitu suatu perkiraan atau penyederhanaan siklus hidrologi dari realitas yang sebenarnya agar mudah dipahami.

\subsection{Model IHACRES}

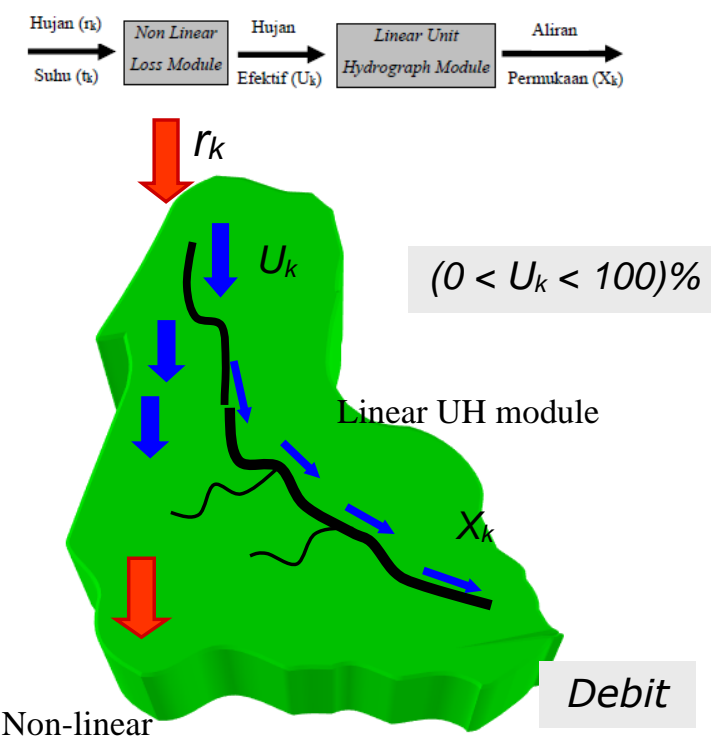

Loss module

Gambar 1. Konsep model IHECRAS

Dapat dilihat dari Gambar 1 mengenai konsep model IHACRES mengenai proses hujan aliran dibedakan menjadi dua. Sub-proses vertical yang digambarkan oleh non-linier-loss-module dan sub-proses lateral yang diimplementasikan melalui linier-unit-hydrograph-module. Non linier loss module berfungsi untuk mengkonversi hujan menjadi hujan efektif. Modul ini bekerja seperti persamaan infiltrasi. Masukan utama modul ini adalah hujan (rk) dan data suhu (tk). Data suhu digunakan untuk menghitung evaporasi didalam DAS. Selanjutnya, hujan efektif (uk) yang dihasilkan dari non linear loss module, ditransfer secara lateral melalui linier unit hydrograph module menjadi aliran permukaan berupa debit terhitung (debit simulasi) di outlet DAS (Indarto,2010).

Menurut Sriwongsitanon dan Taesombat (2011)Untuk menentukan range parameter pada model IHACRES dapat kita lihat sebagai berikut : 
Tabel 1. Range Parameter Model IHACRES

\begin{tabular}{|l|c|}
\hline \multicolumn{1}{|c|}{ Parameter Model } & $\begin{array}{c}\text { Range Parameter } \\
\text { Model }\end{array}$ \\
\hline $\begin{array}{l}\text { Keseimbangan massa ( c } \\
\text { Modulasi temperatur (f) }\end{array}$ & $0,003-0,011$ \\
\hline $\begin{array}{l}\text { Laju pengeringan pada } \\
\text { saat suhu referensi }\left(\tau_{\mathrm{w}}\right)\end{array}$ & $1-9$ \\
\hline $\begin{array}{l}\text { Konstanta waktu respon } \\
\text { cepat }\left(\tau_{\mathrm{q}}\right)\end{array}$ & $0,5-15$ \\
\hline $\begin{array}{l}\text { konstanta waktu respon } \\
\text { lambat }\left(\tau_{\mathrm{s}}\right)\end{array}$ & $2-200$ \\
\hline $\begin{array}{l}\text { Volume perbandingan } \\
\text { untuk aliran lambat }\left(\mathrm{v}_{\mathrm{s}}\right)\end{array}$ & $0,02-0,95$ \\
\hline
\end{tabular}

Dari Tabel 1. Model IHACRES memiliki enam parameter model, tiga diantaranya berkaitan dengan non linear loss module yaitu $\tau_{w}, f$ dan $c$ serta tiga parameter berikutnya berkaitan dengan linear unit hydrograph module yaitu $\tau_{\mathrm{q}}, \tau_{\mathrm{s}}$ dan $\mathrm{v}_{\mathrm{s}}$. Keenam parameter model tersebut dianggap sebagai upaya dalam karakterisasi yang unik dan efisien dari proses hidrologi pada sebuah DAS.

\subsection{Analisis Ketersediaan Air}

Ketersediaan air diasumsikan dengan tersedianya air di sungai, meskipun dalam pengkajian irigasi, curah hujan efektif juga termasuk dalam ketersediaan air. Perhatian utama dalam ketersediaan air adalah pada aliran sungai, tetapi dengan beberapa pertimbangan hujan termasuk di dalamnya (Dep. PU, 1983). Debit air dengan keandalan $50 \%$ biasanya digunakan pada kondisi normal sedangkan $80 \%$ digunakan untuk dibidang irigasi, dengan demikian debit andalan merupakan debit yang diandalkan untuk suatu probabilitas tertentu. Probabilitas untuk debit andalan ini berbedabeda, untuk keperluan irigasi biasa digunakan probabilitas $80 \%$ dapat dihitung menggunakan rumus weibull (Sri Harto, 1993) sebagai berikut:

$\mathrm{P} \%=\frac{m}{n+1} \times 100 \%$

Keterangan:

$\mathrm{P} \%=$ Probabilitas $\%$

$\mathrm{m}=$ Nomor Urut Data

$\mathrm{n}=$ Jumlah Data

\section{METODOLOGI PENELITIAN}

Lokasi Penelitian dilakukan pada aliran Indragiri Hilir . Iuas Das yaitu seluas 4215 $\mathrm{km}^{2}$.

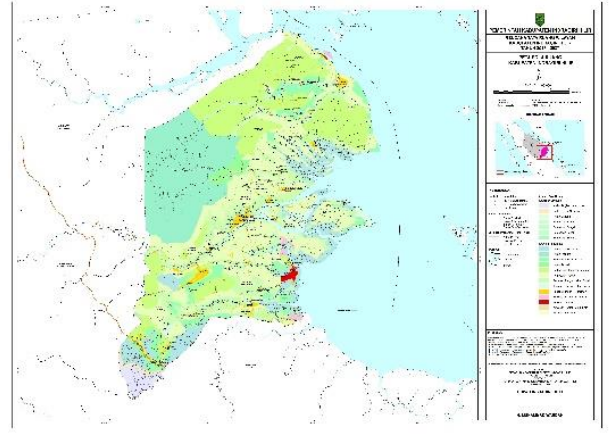

Gambar 2. Peta lokasi penelitian

\subsection{Tahap Pengumpulan Data}

Data sekunder yang digunakan Tahun 2010 hingga Tahun 2015 adalah sebagai berikut:

1. Data curah hujan

Data curah hujan berasal kecamatan Tembilahan mulai dari Tahun 2010 hingga Tahun 2015. Letak geografi stasiun koordinat : $0^{\circ} 19^{\prime} 02^{\prime \prime} \mathrm{LU} / 103^{\circ}$ 10' 00"BT dengan ketinggian dari permukaan laut $2.5 \mathrm{~m}$.

2. Data Klimatologi

Data klimatologi diperoleh dari Stasiun Air Molek. Letak Geografi stasiun koordinat $0^{\circ} 2^{\prime}$ '00" LU / $102^{\circ} 17^{\prime}$ 00"BT dengan ketinggian dari permukaan laut $16 \mathrm{~m}$.

3. Data Debit DAS Indragiri

Data Debit Sungai/AWLR dari stasiun Bt.kuantan rengat yaitu pada Tahun 2010 hungga Tahun 2015. Nomor Stasiun $01-66-0-15$.

\subsection{Analisis Penelitian}

\subsubsection{Uji Konsistensi Data}

Satu seri data curah hujan untuk satu stasiun tertentu, dimungkinkan sifatnya tidak panggah (inconsistent). Data semacam ini tidak dapat langsung dianalisis, karena sebenarnya data di dalamnya berasal dari populasi data yang berbeda. Ketidakpanggahan data ini bisa terjadi karena berbagai sebab, antara lain:

1. alat ukur yang diganti dengan spesifikasi yang berbeda

2. alat ukur dipindahkan dari tempat semula, akan tetapi secara administrasi nama stasiun tidak diubah, misalnya karena masih dalam satu desa yang sama

3. alat ukur sama, tempat tidak dapat dipindahkan tetapi lingkungan berubah. 
Misalnya semula dipasang di tempat yang ideal (sesuai dengan syarat terdahulu), tetapi kemudian berubah karena ada bangunan atau pohon besar yang terlalu dekat.

Jadi sebelum data hidrologi tersebut digunakan, harus dilakukan pengujian terhadap konsistensinya kemudian baru masuk ke tahap kalibrasi data, verifiaksi dan simulasi (Jusatria,2020).

\subsubsection{Kalibrasi Model}

Tahap kalibrasi dilakukan menggunakan Software IHACRES pemilihan periode kalibrasi dan periode warm up. Kalibrasi pada suatu model adalah pemilihan terhadap suatu kombinasi parameter. Poses optimalisasi nilai parameter untuk meningkatkan koherensi atara respon hidrologi DAS yang teramati dan tersimulasi (Bloschl and Grayson, 2000), pemilihan periode kalibrasi diawali dan diakhiri pada keadaan debit relatif kecil sehingga perubahan penyimpanan air di DAS selama periode kalibrasi dapat diasumsikan mendekati nol. Pemilihan periode warm up bertujuan untuk mengisi kondisi awal DAS.

Dalam kalibrasi yang dilakukan, perlu adanya pengecekan kriteria statistik yaitu $\mathrm{R}^{2}$ dan bias sebagai indikator bagus atau tidaknya hasil kalibrasi yang dihasilkan.

Menurut Motovilov, dkk (1999) Untuk menentukan keandalan model adalah $\mathrm{R}^{2}$ dan R. Kedua indikator statistik tersebut cukup dalam mengevaluasi kinerja model dalam hal membandingkan antara hasil simulasi model dengan data yang observasi. Nilai optimal untuk $\mathrm{R}^{2}$ mendekati satu dan bias mendekati nol.

Penyimpangan yang terjadi pada metode $\mathrm{R}^{2}$ (Nash-SutcliffeCoefficient) dapat dirumuskan

$R^{2}=1-\frac{\sum_{i=1}^{n}\left(Q_{S i}-Q_{M i}\right)^{2}}{\sum_{i=1}^{n}\left(Q_{M i}-Q_{m}\right)^{2}} x 100 \%$

Dengan :

$\mathrm{R}^{2} \quad=$ Koefisien $\mathrm{R}^{2}$

$\mathrm{Q}_{\mathrm{Si}}=$ Debit Nilai Simulasi Model ( $\mathrm{m}^{3} /$ detik)

$\mathrm{Q}_{\mathrm{Mi}}=$ Debit terukur ( $\mathrm{m}^{3} /$ detik)

$\mathrm{Q}_{\mathrm{m}}=$ Debit Rata-rata nilai

terukur( $\mathrm{m}^{3} /$ detik)

$\mathrm{n}=$ Jumlah data

$\mathrm{R}^{2}$ memiliki beberapa kriteria seperti yang diperlihatkan pada Tabel 2 .

Tabel 2. Kriteria Nilai terhadap Model IHACRES \begin{tabular}{l|l} 
Nilai R & Interpretasi
\end{tabular}

\begin{tabular}{|c|c|}
\hline $\mathrm{R}^{2}>0,75$ & Baik \\
\hline $0,36<\mathrm{R}^{2}<0,75$ & Memuaskan \\
\hline $\mathrm{R}^{2}<0,36$ & Tidak memuaskan \\
\hline
\end{tabular}

Tabel 3. Kriteria Nilai terhadap koefisien korelasi (R)

\begin{tabular}{|c|c|}
\hline $\begin{array}{c}\text { Nilai Koefisien } \\
\text { Korelasi (R) }\end{array}$ & Interpretasi \\
\hline 0 & Tidak ada Korelasi \\
\hline $0-0,25$ & Sangat Lemah \\
\hline $0,25-0,5$ & Sedang \\
\hline $0,5-0,75$ & Kuat \\
\hline $0,75-0,99$ & Korelasi Sempurna \\
\hline 1 & \\
\hline
\end{tabular}

Bias adalah tingkat kesalahan dalam perhitungan volume aliran atau selisih antara debit terukur dan terhitung per tahun. Perhitungan bias pada IHACRES dirumuskan:

Bias $=\frac{\sum\left(Q_{o}-Q_{m}\right)}{n}$

$Q_{o}=$ debit terukur $\left(\mathrm{m}^{3} /\right.$ detik)

$Q_{m}=$ debit simulasi $\left(\mathrm{m}^{3} /\right.$ detik $)$

$\mathrm{n} \quad=$ jumlah data

\subsubsection{Verifikasi Model}

Verifikasi model merupakan suatu proses setelah tahap kalibrasi selesai dilakukan yang berfungsi untuk menguji kinerja model pada data diluar periode kalibrasi. Kinerja model biasanya lebih baik selama periode kalibrasi dibanding verifikasi, fenomena seperti ini disebut dengan divergensi model. Ketika tingkat divergensi tidak dapat diterima, maka pemodel harus memeriksa struktur model dan prosedur kalibrasi yang sesuai ataupun asumsi yang pantas merevisinya (Wibowo, 2013).

\subsubsection{Simulasi Model}

Tahap simulasi model ini adalah proses terakhir setelah proses kalibrasi dan verifikasi dilakukan yang menggunakan seluruh data dan mampu menggambarkan perilaku yang mungkin terjadi pada sistem nyatanya (jusatria, 2020).

\section{HASIL DAN PEMBAHASAN}

Tahap awal yaitu pengumpulan data sekunder kemudian melakukan uji konsistensi data digunakan untuk menguji 
data lapangan yang diolah konsisten atau tidak. Ketidakpanggahan data suatu stasiun dengan data dari stasiun itu sendiri dengan mendeteksi pergeseran nilai rata - ratanya.

\subsection{Konfigurasi Panjang Data}

Data penelitian yang akan dilakukan selama 6 tahun (2010-2015), oleh sebab itu percobaan kalibrasi selalu dimulai dari tahun 2010, dan verifikasi menyesuaikan tahun setelah kalibrasi.dan simulasi dimulai dari tahun 2010. Dapat dilihat pada Tabel 4 untuk dari skema yang telah ditentukan sebagai berikut:

Tabel 4. Konfigurasi Panjang Data

\begin{tabular}{|l|l|l|l|}
\hline Skema & $\begin{array}{l}\text { Kalibrasi } \\
\text { (Tahun) }\end{array}$ & $\begin{array}{l}\text { Verifikasi } \\
\text { (Tahun) }\end{array}$ & $\begin{array}{l}\text { Simulasi } \\
\text { (Tahun) }\end{array}$ \\
\hline 1 & 2010 & $2011-2015$ & $2010-2015$ \\
\hline 2 & $2010-2011$ & $2012-2015$ & $2010-2015$ \\
\hline 3 & $2010-2012$ & $2013-2015$ & $2010-2015$ \\
\hline 4 & $2010-2013$ & $2014-2015$ & $2010-2015$ \\
\hline 5 & $2010-2014$ & 2015 & $2010-2015$ \\
\hline
\end{tabular}

\subsection{Kosistensi Data Hujan}

Data hujan yang diuji konsistensi dengan panjang data selama 6 tahun

Tabel 5. Perhitungan Konsistensi Data Hujan Stasiun Airmolek dengan Metode RAPS

\begin{tabular}{|c|c|c|c|c|c|c|}
\hline No & Tahun & $\mathrm{R}_{\text {tahunan }}$ & $\mathrm{R}_{\mathrm{i}}-\mathrm{R}_{\text {rerata }}$ & $\mathrm{Sk}^{*}$ & $\mathrm{Sk}^{* *}$ & $\mathrm{Sk}^{* *}$ \\
\hline \hline 1 & 2010 & 1901,9 & 1089,283 & 1089,283 & 1,876 & 1,876 \\
2 & 2011 & 859,5 & 46,883 & 1136,167 & 1,957 & 1,957 \\
3 & 2012 & 804,3 & $-8,317$ & 1127,850 & 1,942 & 1,942 \\
4 & 2013 & 656,5 & $-156,117$ & 971,733 & 1,674 & 1,674 \\
5 & 2014 & 338,5 & $-474,117$ & 497,617 & 0,857 & 0,857 \\
6 & 2015 & 315 & $-497,617$ & 0,000 & 0,000 & 0,000 \\
\hline
\end{tabular}

Qhitungan $<$ Qkritik $=0,799<1,290$ (panggah)

$$
\begin{aligned}
& \mathrm{Q} / \mathrm{n}^{0.5}=\frac{Q}{\sqrt{n}}=\frac{1,957}{6}=0,799 \\
& \mathrm{R} / \mathrm{n}^{0.5}=\frac{R}{\sqrt{n}}=\frac{1,957}{6}=0,799 \\
& R_{\text {hitungan }}^{<} R_{\text {kritik }}=0,799<1,380 \quad \text { ( } \text { panggah) }
\end{aligned}
$$

Berdasarkan perhitungan diatas, dapat disimpulkan bahwa data hujan panggah atau konsisten. Begitupun pada AWLR yang terdapat pada stasiun BT Kuantan Rengat.

\subsection{Analisis Pemodelan Debit}

Tahap kalibrasi dilakukan dengan program IHACRES v.2.1. Hasil nilai $\mathrm{R}^{2}$ dan bias pada tahap kalibrasi dengan variasi warm up untuk masing - masing skema. Diatas analisis pada setiap skema memberikan pemahaman bahwa variasi warm up yang memberikan nilai $\mathrm{R}^{2}$ optimal untuk masing - masing skema tidaklah sama. Sehingga dari warm up dengan $\mathrm{R}^{2}$ optimal tersebut memberikan parameter

Tabel 6. Skema Hasil Percobaan Kalibrasi, Verifikasi IHACRES

\begin{tabular}{|c|c|c|c|c|c|c|}
\hline \multirow{2}{*}{ Skema a } & \multicolumn{3}{|c|}{ Kalibrasi } & \multicolumn{3}{|c|}{ Verifikasi } \\
\cline { 2 - 7 } & $R^{2}$ & $R$ & Bias & $R^{2}$ & $R$ & Bias \\
\hline Skema 1 & 0,526 & 0,543 & 4,173 & $-8,165$ & $-3,652$ & 1179,740 \\
\hline Skema 2 & 0,861 & 0,864 & $-0,701$ & $-4,759$ & $-5,960$ & $-636,068$ \\
\hline Skema 3 & 0,589 & 0,642 & 9,807 & $-2,550$ & $-1,603$ & 1009,248 \\
\hline Skema 4 & 0,188 & 0,174 & $-1,339$ & $-16,893$ & $-1,603$ & 1009,248 \\
\hline Skema 5 & 0,036 & 0,032 & $-0,701$ & $-12,657$ & $-1,603$ & 1009,248 \\
\hline
\end{tabular}

Tabel 7. Skema Hasil Percobaan Simulasi IHACRES

\begin{tabular}{|l|l|l|l|}
\hline \multirow{2}{*}{ Skema } & \multicolumn{3}{|c|}{ Simulasi } \\
\cline { 2 - 4 } & $\mathrm{R}^{2}$ & $\mathrm{R}$ & \multicolumn{1}{c|}{ Bias } \\
\hline Skema 1 & $-3,1634$ & $-1,591$ & 129,2228 \\
\hline Skema 2 & $-5,1235$ & $-7,718$ & $-2076,6275$ \\
\hline Skema 3 & $-3,0449$ & $-4,177$ & $-1023,976$ \\
\hline Skema 4 & $-2,3123$ & $-1,713$ & 1421,0644 \\
\hline Skema 5 & $-1,904$ & $-1,341$ & 522,0546 \\
\hline \multicolumn{2}{|c|}{ Pada tahap kalibrasi nilai } & R2 yang \\
\hline
\end{tabular}
dihasilkan menunjukkan kinerja model yang Baik pada skema 2 ( $R 2>0,75)$, dan nilai $R$ menunjukan kinerja yang sangat kuat dimana nilai $\mathrm{R}(0,75$ - 0,99) sedangkan pada tahap verifikasi dan simulasi kinerja model tidak bagus seperti tahap kalibrasi (jusatria, 2020). 


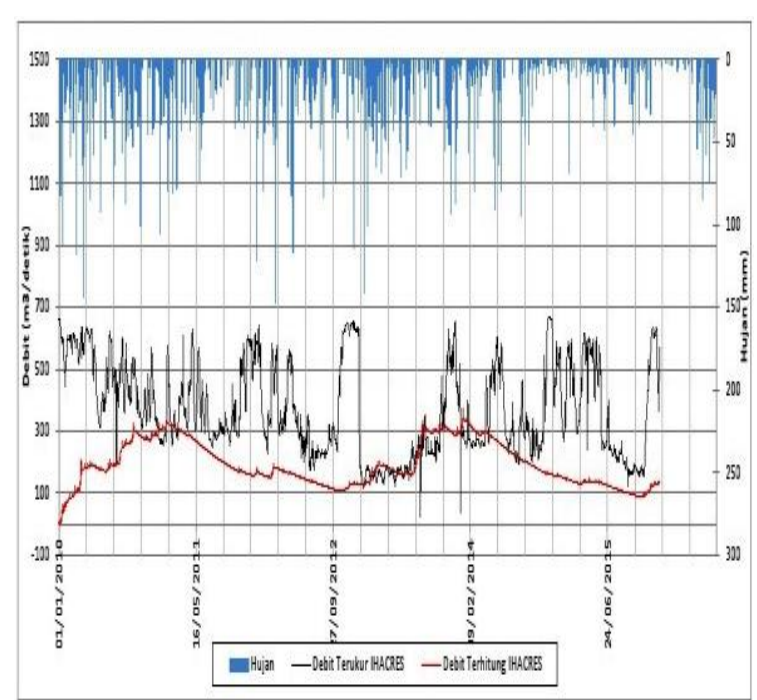

Gambar 3. Grafik hasil verifikasi terbaik Model IHACRES Skema 3

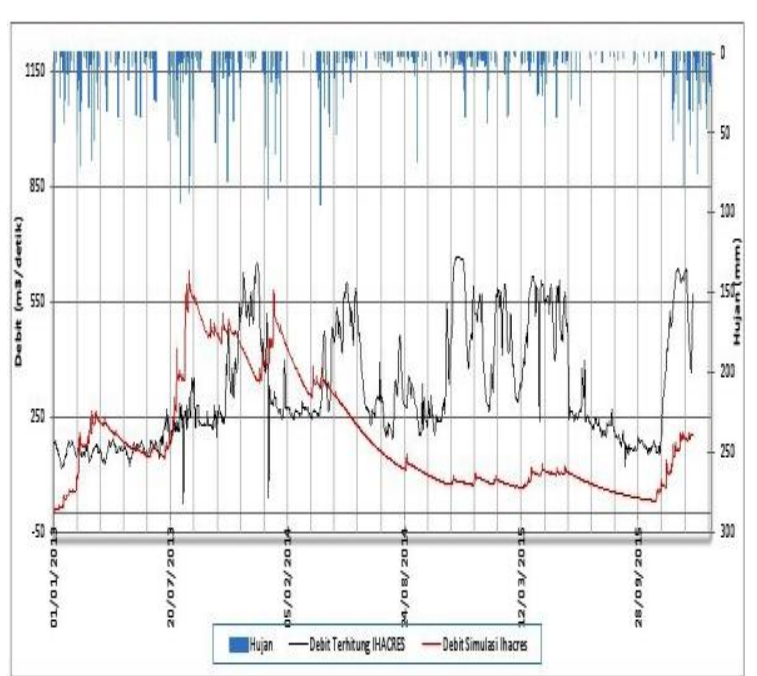

Gambar 4. Grafik hasil simulasi terbaik Model IHACRES Skema 5

\subsection{Analisis Ketersediaan Air}

Tabel 8. Probailitas Debit Andalan

\begin{tabular}{|l|l|l|l|l|l|l|l|l|l|l|l|l|l|}
\hline $\begin{array}{l}\text { No. } \\
\text { Urut } \\
\text { Data }\end{array}$ & $\begin{array}{l}\text { Prob. } \\
{[\%]}\end{array}$ & Jan & Feb & Mar & Apr & Mei & Jun & Jul & Agt & Sept & Okt & Nop & Des \\
\hline 1 & $14 \%$ & 26,16 & 27,01 & 14,85 & 27,58 & 13,21 & 10,63 & 16,34 & 13,77 & 13,69 & 13,50 & 85,30 & 14,50 \\
\hline 2 & $20 \%$ & 11,26 & 12,22 & 12,42 & 18,45 & 9,65 & 8,53 & 14,32 & 7,90 & 9,00 & 9,10 & 20,16 & 12,81 \\
\hline 3 & $29 \%$ & 8,33 & 8,61 & 8,76 & 9,83 & 8,48 & 8,32 & 8,09 & 7,68 & 8,15 & 8,34 & 18,15 & 9,83 \\
\hline 4 & $43 \%$ & 7,92 & 8,21 & 8,58 & 9,18 & 8,00 & 8,21 & 7,82 & 7,57 & 7,90 & 7,59 & 9,09 & 8,87 \\
\hline 5 & $50 \%$ & 7,72 & 8,01 & 8,49 & 9,02 & 7,76 & 7,39 & 7,73 & 4,50 & 7,82 & 7,22 & 8,79 & 8,43 \\
\hline 6 & $71 \%$ & 5,04 & 7,42 & 4,61 & 8,95 & 3,50 & 3,80 & 7,55 & 2,65 & 7,65 & 3,22 & 8,63 & 8,21 \\
\hline 7 & $80 \%$ & 4,00 & 4,33 & 1,23 & 0,34 & 2,71 & 1,68 & 3,66 & 1,84 & 2,70 & 2,80 & 4,37 & 2,72 \\
\hline
\end{tabular}

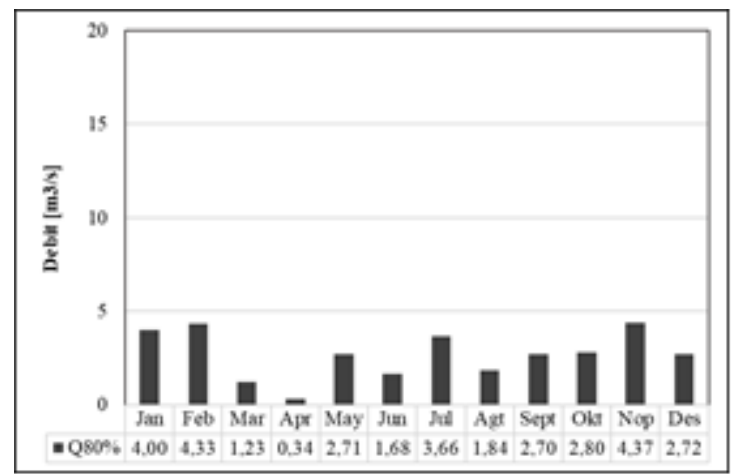

Gambar 5. Grafik distribusi Debit untuk probabilitas $80 \%$

Dapat dilihat pada Gambar 5 hasil debit andalan untuk keperluan irigasi dengan probabilitas $80 \%$ debit maksimum terjadi pada bulan Februari sebesar $4,33 \mathrm{~m}^{3} / \mathrm{s}$ dan debit minimum terjadi pada bulan April sebesar $0,34 \mathrm{~m}^{3} / \mathrm{s}$.

\section{KESIMPULAN DAN SARAN}

Ketersediaan air pada DAS Indragiri Hilir berdasarkan hasil analisis untuk keperluan irigasi dengan probabilitas $80 \%$ debit maksimum terjadi pada bulan Februari sebesar $4,33 \mathrm{~m}^{3} / \mathrm{s}$ dan debit minimum terjadi pada bulan April sebesar 0,34 $\mathrm{m}^{3} / \mathrm{s}$. Secara keseluruhan ketersediaan air di lokasi tersedia sepanjang tahun. tetapi tidak bisa digunakan untuk kebutuhan PLTA karena terbatasnya data debit yang tersedia mungkin dipengaruhi faktor pasang surut. Saran dalam penelitian ini mungkin bisa menggunakan model rainfall-runoff lainnya dan menggunakan banyak stasiun hujan.

\section{UCAPAN TERIMA KASIH}

Terimakasih kepada pada BWSS III atas pemberian data-data untuk melengkapi penelitian ini. 


\section{DAFTAR PUSTAKA}

[1] Indarto, "Hidrologi Dasar Teori dan Contoh Aplikasi Model Hidrologi," Bumi askara,Jakarta, 2011.

[2] Motovilov, Y.G., Gottschalk, L., Engeland, K. \& Rodhe, Validation of a Distributed Hydrological Model Against Spatial Observations, Elsevier Agricultural and Forest Meteorology. 98 : 257-277, 1999.

[3] Sriwongsitanon, N. \& Taesombat, "Estimation of the IHACRES Model Parameters for Flood Estimation of Ungauged in the Upper Ping River Basin," Kasetsart J (Nat. Sci.) 45,2011.
[4] Sri Harto, Analisa Hidrologi, PT Gramedia Pustaka Utama, jakarta, 1993

[5] Wibowo Rian A, Analisa Hujan Aliran Menggunakan Model IHACRES. Skripsi S1.Program Studi Teknik Sipil, Universitas Riau, Pekanbaru, 2013.

[6] Jusatria, Analisis ketersediaan air pada DAS kampar menggunakan model IHACRES, Universitas Riau, Pekanbaru, 2020.

[7] Jusatria, Analisis Model Konseptual Debit Air pada DAS Indragiri Hilir Menggunakan Model IHACRES. 